\title{
O Instituto de Patentes Pipeline e o Acesso a Medicamentos: Aspectos Econômicos e Jurídicos Deletérios à Economia da Saúde
}

PIPELINE PATENTS AND ACCESS TO DRUGS: ECONOMIC AND LEGAL ASPECTS DELETERIOUS TO HEALTH ECONOMY

\author{
Lia Hasenclever ${ }^{(*)}$ \\ Rodrigo Lopes $(* *)$ \\ Gabriela Costa Chaves( $(* * *)$ \\ Renata Reis $(* * * *)$ \\ Marcela Fogaça Vieira(*****)
}

\section{RESUMO}

A criação da OMC trouxe consigo uma série de acordos multilaterais, entre os quais o Acordo TRIPS que regula temas relacionados à propriedade intelectual. A partir de sua adoção, estabeleceu-se um "padrão mínimo" de proteção, incluindo a ampliação do escopo de patenteabilidade para todos os campos tecnológicos. O Brasil, ao buscar adequar-se ao TRIPS, foi além das obrigações assumidas ao incluir o instituto conhecido como patentes pipeline: um dispositivo temporário por meio do qual foram aceitos depósitos de patentes em campos tecnológicos não reconhecidos anteriormente, entre os quais o setor farmacêutico. Por este instituto, foram

${ }^{*}$ ) Economista, mestre em Economia Industrial, doutora em Engenharia de Produção; professora e pesquisadora do Grupo de Economia de Inovação, do Instituto de Economia, da Universidade Federal do Rio de Janeiro.

$\left.{ }^{* *}\right)$ Economista, mestrando em Políticas Públicas, Estratégias e Desenvolvimento pela Universidade Federal do Rio de Janeiro.

${ }^{* * *}$ ) Mestre em Saúde Pública pela Escola Nacional de Saúde Pública Sergio Arouca (ENSP) da Fundação Oswaldo Cruz. Farmacêutica da Campanha de Acesso a Medicamentos Essenciais dos Médicos Sem Fronteiras (MSF). E-mail: gabriela.chaves@ rio.msf.org

${ }^{* * * *}$ ) Advogada da Associação Brasileira Interdisciplinar de AIDS (ABIA); coordenadora do Grupo de Trabalho sobre Propriedade Intelectual (GTPI)/REBRIP e doutoranda em Políticas Públicas, Estratégias e Desenvolvimento pela Universidade Federal do Rio de Janeiro.

${ }^{* \star \star \star \star}$ ) Advogada da Conectas Direitos Humanos; pós-graduada em Direito da Propriedade Intelectual e Novas Tecnologias da Informação pela Fundação Armando Álvares Penteado - FAAP.

Recebido em 01.04.10. Aprovado em 15.04.10. 
realizados 1.182 pedidos, entre os quais se encontram vários medicamentos que hoje são fundamentais para o enfrentamento de problemas de saúde pública. O presente artigo tem como objetivo discutir patentes pipeline a partir de duas perspectivas: da economia da saúde e do direito. Do lado econômico, o artigo traz um estudo do cálculo econômico de um sobrepreço que o Brasil pagou por medicamentos de AIDS, sem contrapartida de aumento de investimento em P\&D. Do lado do direito, observa-se que o instituto das patentes pipeline viola uma série de princípios constitucionais e também tratados internacionais dos quais o Brasil é signatário. Ao final, o artigo aborda como este mecanismo vem sendo tratado por diferentes atores da sociedade, tendo como foco de análise a Ação Direta de Inconstitucionalidade, proposta em 2009, pelo Procurador-geral da República no Supremo Tribunal Federal. O artigo conclui que a introdução do instituto da patente pipeline é frontalmente contra o interesse público.

\section{Palavras-chave}

Economia da Saúde; Patentes Farmacêuticas; Patentes Pipeline; Propriedade Intelectual; Supremo Tribunal Federal.

\section{ABSTRACT}

The creation of the WTO has brought a series of multilateral agreements, including the TRIPS Agreement that regulates matter related to intellectual property rights. The Agreement established a "minimum standard" of protection, including the expansion of the scope of patentability for all fields of technology. Brazil, seeking to be TRIPS complied, went beyond its international obligations and included a mechanism known as pipeline patents: a temporary mechanism through which were accepted patents in fields of technology not previously recognized, including the pharmaceutical sector. 1182 patent applications were filled through this mechanism, among which are several medicines that are fundamental to public health. This article intends to discuss the pipeline patents from two perspectives: health economics and law. From the economic side, this paper presents a study that calculates the higher prices that Brazil paid for AIDS drugs, without any counterpart in investment on R\&D. On the side of law, the pipeline patents are against a number of constitutional principles and also international treaties to which Brazil is a signatory. Finally, the article discusses how this mechanism has been handled by different actors of society, focusing on the analysis of direct action of unconstitutionality, proposed in 2009 by the Attorney General's Office in the Supreme Court. The article concludes that the introduction of the pipeline patent mechanism is frontally against the public interest. 


\section{Keywords}

Brazilian Supreme Court; Health Economy; Intellectual Property Rights; Pharmaceutical Patents; Pipeline Patents.

\section{INTRODUÇÃO}

A criação da Organização Mundial do Comércio (OMC), em dezembro de 1994, trouxe consigo uma série de acordos multilaterais que foram firmados por seus Estados Membros. É considerada a única organização internacional que estabelece "normas comerciais em nível mundial com efeitos vinculantes para seus Membros"(1), ou seja, essas normas não são recomendatórias, mas sim obrigatórias e, por isso, tiveram que ser incorporadas no arcabouço legal dos países. O Acordo sobre os Aspectos dos Direitos de Propriedade Intelectual Relacionados ao Comércio da OMC - conhecido como Acordo TRIPS ou ADPIC — regula temas que estão relacionados à propriedade intelectual. A partir de sua adoção, estabeleceu-se uma espécie de "padrão mínimo" de proteção, o que incluiu a ampliação do escopo de patenteabilidade para todos os campos tecnológicos e a extensão da duração das patentes para 20 anos. A ideia inicial de "padrão mínimo" não representa um afrouxamento do sistema de propriedade intelectual, mas sim um enrijecimento que pode ser ainda fortalecido de outras maneiras, como pela própria legislação nacional de cada país e por tratados de livre comércio bilaterais e regionais.

O Acordo TRIPS também estabeleceu algumas disposições transitórias para adequação ao novo regime mundial de propriedade intelectual, levando em consideração o nível de desenvolvimento de cada país membro. Assim, países em desenvolvimento que não reconheciam patentes para produtos e processos farmacêuticos, entre outros, teriam até 2005 para fazê-lo. Por outro lado, estabeleceu que os países que fossem utilizar o referido período de transição deveriam criar um mecanismo interno para aceitar os pedidos de patentes nessas áreas a partir da entrada em vigor do TRIPS - 10 de janeiro de 1995. Tais pedidos somente seriam analisados no país depois de finalizado o período de transição, resguardando a data do depósito no país de origem ${ }^{(2)}$ e observando o período de anterioridade de um ano. Este mecanismo ficou conhecido como mailbox e teve como objetivo proteger as

(1) CONECTAS DIREITOS HUMANOS. Organizações contestam a constitucionalidade da Lei de Propriedade intelectual, 29 nov. 2007. p. 13. Disponível em: <http://www.conectas.org/ noticia.php?not_id=192>. Acesso em: 22 jan. 2008.

(2) BRASIL. Decreto n. 1.355, de 30 de dezembro de 1994. Promulga a ata final que incorpora os resultados da rodada Uruguai de negociações comerciais multilaterais do GATT. Diário Oficial [da] República Federativa do Brasil, Poder Executivo, Brasília, DF, 31 dez. 1994. 
empresas que já tivessem feitos seus pedidos de patentes nos países onde já se concediam proteção nessas novas áreas ${ }^{(3)}$.

O Brasil buscou adequar-se ao TRIPS por meio da aprovação da Lei 9.279/96 (LPI), em vigor a partir de maio de 1997. Dentre as mudanças marcantes no novo sistema nacional de propriedade industrial, destacamos a ampliação do patenteamento para todos os campos do conhecimento, incluindo a área farmacêutica ${ }^{(4)}$. Importante observar que o legislativo brasileiro optou por não utilizar plenamente o período de transição concedido pelo TRIPS e foi além da previsão de incorporação do dispositivo temporário mailbox, ao incluir o instituto conhecido como patentes pipeline (arts. 230 e 231 da Lei 9.279/96).

Trata-se de um dispositivo igualmente temporário por meio do qual foram aceitos depósitos de patentes em campos tecnológicos não reconhecidos, até então, no Brasil, desde que os produtos não estivessem sendo comercializados em qualquer mercado ou que estivessem sendo feitos efetivos esforços para a exploração local do objeto no país.

Diferentemente do mailbox, o instituto da patente pipeline permitiu o depósito de pedidos mesmo fora do período de prioridade e não exigiu o exame técnico do pedido de patente no Brasil, sendo que a concessão desses pedidos ficou atrelada somente à decisão favorável à patenteabilidade no país onde havia sido feito o primeiro depósito. Desse critério, ficaram excluídos os depósitos cujos inventores fossem nacionais, para os quais o exame deveria ser efetuado normalmente, considerando os requisitos de novidade, atividade inventiva e aplicação industrial.

O instituto da patente pipeline visou alcançar os inventores que não tiveram seus objetos de invenção contemplados no Código de Propriedade Industrial brasileiro anterior. Assim, aqueles que já haviam depositado suas invenções na vigência do antigo Código, ainda que as mesmas não pertencessem ao rol de matérias patenteáveis no Brasil na época, puderam também ser contemplados, desde que desistissem do depósito anterior e apresentassem novo pedido, adequados ao instituto pipeline.

O resultado da incorporação desse dispositivo na nova legislação brasileira foi o depósito de 1.182 pedidos de patentes ${ }^{(5)}$, entre as quais encontram-se vários medicamentos que, hoje, são considerados essenciais ou fundamentais para o enfrentamento de problemas de saúde pública, como será visto a seguir.

(3) CHAUDHURI, S. Globalization of patent laws: flexibilities under TRIPS and changes in pharmaceutical patents in India. In: THE WTO and India's pharmaceuticals industry: patent protection, TRIPS and developing countries. Oxford: Oxford University Press, 2005.

(4) BRASIL. Lei n. 9.279, de 14 de maio de 1996. Regula direitos e obrigações relativos a propriedade industrial. Diário Oficial [da] República Federativa do Brasil, Poder Executivo, Brasília, DF, 15 mai. 1996.

(5) BERMUDEZ, J. A. Z.; EPSZTEJN, R.; OLIVEIRA, M. A.; HASENCLEVER, L. O Acordo TRIPS da $O M C$ e a proteção patentária no Brasil: mudanças recentes e implicações para a produção local e o acesso da população aos medicamentos. Rio de Janeiro: FIOCRUZ/ENSP, 2000. 
O presente artigo tem como objetivo discutir o instituto das patentes pipeline a partir de duas perspectivas: da economia da saúde e do direito. Acredita-se que elas sejam convergentes e complementares, e que contribuam para o enriquecimento do debate a respeito dos interesses favorecidos e prejudicados após aprovação do novo marco regulatório de propriedade intelectual no Brasil. Ademais, pretende-se descrever e discutir como este mecanismo vem sendo questionado por diferentes atores da sociedade, tendo como foco de análise a Ação Direta de Inconstitucionalidade (ADI 4.234), proposta em 2009, pelo Procurador-geral da República no Supremo Tribunal Federal.

O artigo está dividido em quatro seções, além desta introdução e das considerações finais. As duas primeiras tratam de aspectos relacionados à economia da saúde, a terceira trata dos aspectos relacionados ao direito e a última trata da ADI 4.234.

\section{O ACESSO A MEDICAMENTOS ANTIRRETROVIRAIS (ARV), O INSTITUTO DA PATENTE PIPELINE E A LICENÇA COMPULSÓRIA}

A Constituição Federal de 1988 ao afirmar que "saúde é direito de todo cidadão e dever do Estado" forneceu as bases fundamentais para a construção do Sistema Único de Saúde (SUS) por meio das Leis ns. 8.080/90 e 8.142/90. A partir de então, apresentou-se o desafio de desenvolver um sistema público de saúde obedecendo a princípios fundamentais, como a universalidade do acesso aos serviços de saúde em todos os níveis de assistência, a integralidade da assistência, a igualdade da assistência à saúde, a participação da comunidade, a descentralização político-administrativo, entre outros. Entre os campos de atuação do SUS está a assistência terapêutica integral, incluindo a farmacêutica (art. 6 da Lei n. 8.080/90). Esta última, considerando a amplitude e complexidade, também se transformou em compromisso político de longo prazo por meio da Portaria 3.916/96 - a Política Nacional de Medicamentos - materializando diretrizes e prioridades para a garantia do acesso a medicamentos essenciais e de qualidade.

No âmbito da epidemia de HIV/Aids no Brasil, a Lei n. 9.313/96 fortaleceu o arcabouço legal já existente para a garantia do acesso a antirretrovirais (ARVs) e outros medicamentos para o tratamento da infecção. A aprovação da referida lei foi determinante para a melhor estruturação do Programa Nacional de DST/Aids, pois demandou a organização de um sistema logístico para aquisição e distribuição de medicamentos envolvendo as três esferas de governo ${ }^{(6)}$.

(6) OLIVEIRA, M. A.; ESHER, A. Acesso universal ao tratamento para as pessoas vivendo com HIV e AIDS no Brasil. In: BERMUDEZ, Jaz; OLIVEIRA, M. A.; ESHER, A. (Orgs.). Acceso a medicamentos: derecho fundamental, papel del Estado. Rio de Janeiro: ENSP/FIOCRUZ, 2004. 
Outro elemento que contribuiu sobremaneira para a implementação da política de acesso a medicamentos foi a produção local e nacional dos medicamentos ARVs em virtude de o país não reconhecer patentes para o setor farmacêutico até 1996. A produção nacional forneceu ao governo a opção de adquirir produtos a preços inferiores aos que estavam sendo praticados no mercado internacional pelos detentores das patentes ${ }^{(7)}$.

Do ponto de vista da saúde pública, isso representou maior segurança na aquisição, o acesso no longo prazo e, também, a possibilidade de incorporar novos pacientes no tratamento medicamentoso, representando uma melhora radical na qualidade de vida das pessoas que vivem com HIV/Aids. Efeitos adicionais dessa medida incluem um aumento da credibilidade dos serviços de saúde(8).

A entrada em vigor da nova lei de propriedade industrial (Lei n. 9.279/96) a partir de 1997 interrompeu de forma prematura esse processo de produção local ao não se valer do uso da prerrogativa do período de transição previsto no acordo TRIPS e também incluir a possibilidade do instituto da patente pipeline.

Dentre os 19 ARVs fornecidos pelo Ministério da Saúde, oito não são protegidos por patentes e por isso são produzidos por laboratórios nacionais públicos e privados ${ }^{(9)}$. Os demais são patenteados ou sujeitos à proteção patentária no Brasil (há o depósito do pedido, mas sem decisão quanto à patenteabilidade) e, por isso, são importados de empresas farmacêuticas transnacionais. Dentre estes, estão alguns que foram protegidos por meio do instituto da patente pipeline, como são os casos do lopinavir/ritonavir (Abbott), abacavir (GlaxoSmithKline - GSK), efavirenz (Merck), nelfinavir (Roche) e amprenavir (Vertex) $)^{(10)(11)}$.

Coincidentemente, a maioria dos medicamentos protegidos pelo instituto da patente pipeline foi alvo de problemas relacionados ao acesso, das mais diversas naturezas, em especial porque o governo ficou limitado à possibilidade de compra dos produtos de apenas uma empresa ofertante para cada um deles, ou seja, a empresa detentora da patente.

(7) HASENCLEVER, L (Coord.). O Programa brasileiro de combate à AIDS e a experiência brasileira na produção local de medicamentos anti-retrovirais. Rio de Janeiro: UFRJ/ANRS, 2003. Mimeo.

(8) OLIVEIRA, M. A.; ESHER, A.op. cit.

(9) ORSI, F.; HASENCLEVER, L; FIALHO, B.; TIGRE, P.; CORIAT, B. Intellectual property rights, anti-AIDS policy and generic drugs: lessons from brazilian public health program. In: MOATTI, J. P. et al. (Ed.). Economics of AIDS and Access to HIVIAIDS care in developing countrie: issues and Challenges. Paris: ANRS, 2003. v. 1, p. 109-135.

(10) CORIAT, B.; ORSI, F.; ALMEIDA, C. TRIPS and the international public health controversies: issues and challenges. Industrial and Corporate Change Advance Access, Oxford, v. 15, n. 6, p. 1 30, Nov. 2006.

(11) MÉDICOS SEM FRONTEIRAS. Guia de Preços para a Compra de ARVs para os países em desenvolvimento: untangling the web. 9. ed. Rio de Janeiro: MSF, 2006. Disponível em: <http:// www.msf.org.br/campanha/guia_precos06.pdf>. 
Conforme evidenciam Granjeiro et al. ${ }^{(12)}$, a entrada do nelfinavir, em 1998, e do efavirenz, em 1999, no protocolo de tratamento do Ministério da Saúde, representou um marco na incorporação de medicamentos protegidos por patentes.

Em 2001 e 2003, os medicamentos lopinavir/ritonavir, efavirenz e nelfinavir foram alvo de negociações de preços entre o Ministério da Saúde e as empresas detentoras das patentes em virtude do forte impacto que o consumo dos mesmos - de aproximadamente $60 \%$ - representava no orçamento para compra de ARVs. Reduções de preço consideradas satisfatórias foram alcançadas, em especial, porque o governo tinha como principal instrumento a ameaça de licenciamento compulsório e possibilidade de produção local(13)(14)(15).

Em 2005, após tentativa infrutífera de redução do preço mediante negociação com a empresa, foi declarado o interesse público do medicamento lopinavir/ritonavir, etapa anterior à emissão de uma licença compulsória. No entanto, o governo não emitiu a licença compulsória e firmou um acordo bilateral com a empresa Abbott, incluindo cláusulas abusivas como a restrição para o uso da licença compulsória, a fixação do preço do medicamento até 2011 com uma redução ínfima e o aumento no preço da nova formulação termoestável em $10 \%{ }^{(16)}$.

Em abril e maio de 2007, o governo brasileiro declarou o interesse público ${ }^{(17)}$ do medicamento efavirenz e a posterior licença compulsória(18). $O$ governo tentou negociar várias vezes com a empresa detentora da patente - a Merck - para a redução do preço do medicamento. Foram considerados, nestas negociações, o compromisso com o acesso universal, o tamanho da demanda, o constante aumento de preços e o fato de a empresa praticar um preço superior ao praticado em outros países de igual nível de desenvolvimento. Segundo afirmam representantes do governo, além das propostas

(12) GRANJEIRO, A.; TEIXEIRA, L.; BASTOS, F. I. et al. Sustentabilidade da política de acesso a antirretrovirais no Brasil. Revista de Saúde Pública, São Paulo, v. 40 (supl.), p. 60-69, abr. 2006. (13) BERMUDEZ, Jaz; OLIVEIRA, M. A; CHAVES, G. C. O acordo TRIPS da OMC e os desafios para a saúde pública. In: BERMUDEZ, Jaz; OLIVEIRA, M. A; ESTHER, A. (Org.). Acceso a medicamentos: derecho fundamental, papel del Estado. Rio de Janeiro: ENSP/FIOCRUZ, 2004. p. 69-89.

(14) ORSI, F.; HASENCLEVER, L; FIALHO, B.; TIGRE, P.; CORIAT, B. op. cit., p. 109-136.

(15) GRANJEIRO, A.; TEIXEIRA, L.; BASTOS, F. I. et al. op. cit.

(16) GRUPO DE TRABALHO SOBRE PROPRIEDADE INTELECTUAL. Por que o Brasil paga mais por medicamentos importantes para a saúde pública? Rio de Janeiro: GTPI, 2006. Disponível em: <http:/ /www.abiaids.org.br/_img/media/patentes_GTPI.pdf>.

(17) BRASIL. Portaria no 879 de 24 de abril de 2007. Declara de interesse público os interesses de patentes sobre o efavirenz, para fins de licença compulsória para uso público não comercial. Disponível em: <https://www.in.gov.br/materias/xml/do/secao1/2664533.xml>.

(18) BRASIL. Presidência da República. Casa Civil. Decreto n. 6.108, de 4 de maio de 2007. Concede licenciamento compulsório, por interesse público, de patentes referentes ao Efavirenz, para fins de uso público não-comercial. Diário Oficial da União, 7 maio 2007. Disponível em: <http:// www.planalto.gov.br/CCIVIL_03/_Ato2007-2010/2007/Decreto/D6108.htm>. 
insatisfatórias, a empresa estava buscando postergar ao máximo as negociações para que a adoção de medidas para a aquisição de versões genéricas mais baratas do medicamento, por meio da importação, não fosse mais viável.

Outra forma de comprometimento do abastecimento decorrente do monopólio pode ser ilustrada pelos exemplos a seguir. Em fevereiro de 2007, - Programa Nacional de DST/Aids divulgou uma nota técnica ${ }^{(19)}$ orientando às coordenações estaduais e aos profissionais de saúde a não prescrever o antirretroviral abacavir $300 \mathrm{mg}$, diante da possibilidade de atraso na entrega do referido medicamento. O motivo informado foi um problema no contrato para 2007, imputados exclusivamente ao laboratório fornecedor. Como medida temporária até a regularização do abastecimento, foi recomendada a não iniciação de novos tratamentos com o medicamento, assim como a utilização de outras opções em casos de substituição. No entanto, muitos médicos modificaram a terapia de seus pacientes, o que teve um caráter irreversível e significou, para muitos, a diminuição do escopo de opções de tratamento. Mesmo com a existência de quatro fabricantes de versões genéricas $^{(20)}$, o país ficou impossibilitado de fazer a importação em caráter de urgência, a não ser que emitisse uma licença compulsória.

Em junho de 2007, a empresa Roche comunicou ao Ministério da Saúde o recolhimento do medicamento Mesilato de Nelfinavir (comercializado pela

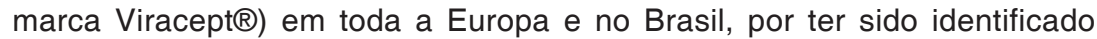
problemas na qualidade do produto. Novamente, como medida temporária, o Ministério da Saúde suspendeu a distribuição do nelfinavir e recomendou a substituição do medicamento por outro antirretroviral. Mesmo com a existência de três fabricantes indianos de versões genéricas, possíveis fornecedores opcionais, o país se encontrou novamente refém de apenas uma opção de oferta, cuja patente foi concedida pelo mecanismo do instituto da patente pipeline. Estes exemplos ilustram outra maneira de como o monopólio de medicamentos no mercado brasileiro acarreta consequências negativas para o acesso, que são diferentes da prática de preços abusivos.

Nesse sentido, fica evidente o prejuízo causado pelas patentes concedidas pelo instituto da patente pipeline do ponto de vista do direito à garantia do acesso à saúde, especificamente, aos medicamentos essenciais.

Além dos aspectos já apresentados, no que tange ao impacto para a saúde pública, o instituto de patentes pipeline também teve impacto em aspectos econômicos e de desenvolvimento tecnológico nacional. O incentivo ao setor farmacêutico local é elemento imperativo para a regulação do monopólio que a concessão de patentes acarreta.

(19) Nota Técnica n. 18/07 de 1ำ de fevereiro de 2007 da Unidade de Assistência e Tratamento do Programa Nacional de DST e AIDS do Ministério da Saúde.

(20) MÉDICOS SEM FRONTEIRAS. Guia de Preços para a Compra de ARVs para os países em desenvolvimento: untangling the web, cit. 


\section{OS MERCADOS MONOPOLISTAS, O DESENVOLVIMENTO TECNOLÓGICO E O INSTITUTO DAS PATENTES PIPELINES}

No campo da economia, a justificativa do instituto da patente é um trade-off entre o público e o privado: aquele que investiu em pesquisa e desenvolvimento e logrou um resultado prático — o produtor inovador — terá o direito de obter um monopólio da comercialização desse resultado, mas tem a obrigação de revelar o conhecimento pelo qual obteve o "produto" inovador por meio do documento de patentes que será posto à disposição do público em geral, aumentando o estoque de conhecimento da sociedade. $O$ objetivo primordial desta troca entre o público e o privado é o de estimular o investimento privado em inovação, já que a natureza do conhecimento é pervasiva e poderia ser aproveitada por todos sem ganhos de reembolso para o investidor(21)(22). Acredita-se que o recebimento deste prêmio pelo produtor da inovação seja uma forma de levar os agentes privados a investirem em um bem que poderia, do contrário, ser apropriado por todos sem remunerar os investimentos. Trata-se da chamada "teoria do estímulo"(23) que reconhece ao inventor o direito exclusivo para exploração como forma de recuperar os investimentos feitos para o desenvolvimento da invenção, através da acumulação de uma renda de monopólio ao longo da vigência da patente. Considera, portanto, que a patente seja uma forma de estímulo ao desenvolvimento de inovações, um preço prêmio para o produtor inovador.

O instituto de patente pipeline, entretanto, não representa um bem- estar adicional para a sociedade, seja porque ele não incentivará novos investimentos em Pesquisa e Desenvolvimento (P\&D) (benefício de apropriação privada), seja porque ele não acrescentará novos conhecimentos para a sociedade (benefício de apropriação pública). Este instituto está protegendo investimentos pretéritos em P\&D que já ocorreram e que, portanto, não precisam ser mais incentivados. Da mesma forma, a difusão do conhecimento já é um fato decorrido. Em suma, ele não traz benefícios privados ou públicos para a sociedade, mas os contraria frontalmente, reduzindo o bem-estar econômico de uns - a sociedade em geral - e privilegiando o de outros - os produtores inovadores. Dessa forma, é evidente que o instituto da patente pipeline é contrária à natureza econômica do instituto de patente: o país pagou como "contrapartida" preços altos para muitos dos produtos protegidos, como é o caso dos ARV, sem que esses estimulassem novos investimentos em P\&D ou ampliassem o conhecimento disponível.

(21) ARROW, K. J. The economic implications of learning by doing. Review of Economic Studies, $\mathrm{n}$. 29, p. $155-173,1962$.

(22) NELSON, R. R. The simple economics of basic scientific researc. The Journal of Political Economy, Chicago, v. 297, n. 67, 1959.

(23) OLIVEIRA, U. M. A proteção jurídica das invenções de medicamentos e de gêneros alimentícios. Porto Alegre: Síntese, 2000. 
Como forma de dimensionar, em valores monetários, o prejuízo hipotético do instituto da patente pipeline para o Brasil, foi selecionada uma amostra intencional dos cinco ARV protegidos pelo mecanismo, nas formulações distribuídas pelo Ministério da Saúde e com informações sobre as quantidades e os preços das compras disponibilizados pelo Sistema Integrado de Orçamento Público de Saúde (SIOPS) no período entre 2001 e 2007. A Tabela 1 apresenta esses valores com base no dólar de 2006. No período considerado, as compras públicas desses medicamentos montaram a cerca de US\$705 milhões. O raciocínio utilizado neste texto para o cálculo do prejuízo hipotético foi o de que, se não existisse o instituto da patente pipeline, não se teria pago royalties às empresas detentoras das patentes. Em outras palavras, no montante pago pela aquisição de medicamentos entre 2001 e 2007 há uma parte adicional que corresponde às receitas de royalties, que não existiriam se as patentes pipelines não tivesse sido concedidas.

\section{Tabela 1: Valor total das aquisições de antiretrovirais através do instituto da patente pipeline, 2001-2007 (US\$ de 2006)}

\begin{tabular}{|l|r|r|r|r|r|}
\hline \multicolumn{1}{|c|}{ Medicamento } & \multicolumn{2}{|c|}{$\begin{array}{c}\text { Período de aquisições } \\
\text { coberto }\end{array}$} & $\begin{array}{l}\text { Quantidade do } \\
\text { medicamento } \\
\text { comprado }\end{array}$ & $\begin{array}{c}\text { Preço/ } \\
\text { unidade } \\
\text { (US\$) }\end{array}$ & $\begin{array}{r}\text { Valor } \\
\text { total } \\
\text { (US\$) }\end{array}$ \\
\hline Abacavir Sol.Oral & $28 / 2 / 2002$ & $26 / 7 / 2007$ & 17.395 & 46,30 & $805.388,50$ \\
\hline Abacavir 300mg & $5 / 8 / 2004$ & $29 / 6 / 2006$ & 5.069 .220 & 2,56 & $12.977 .203,20$ \\
\hline Amprenavir Sol.Oral & $23 / 3 / 2001$ & $8 / 8 / 2006$ & 17.636 & 102,64 & $1.810 .159,04$ \\
\hline Amprenavir 150mg & $23 / 3 / 2001$ & $8 / 8 / 2006$ & 9.206 .280 & 0,85 & $7.825 .338,00$ \\
\hline Efavirenz 600mg & $11 / 03$ & $2 / 5 / 2006$ & 91.900 .012 & 2,160 & $198.504 .025,92$ \\
\hline Efavirenz 200mg & $02 / 02$ & $2 / 5 / 2006$ & 33.161 .751 & 1,06 & $35.151 .456,06$ \\
\hline Efavirenz sol.oral & $04 / 03$ & $2 / 5 / 2006$ & 74.129 & 32,80 & $2.431 .431,20$ \\
\hline Lopinavir/r 133/33mg & $22 / 2 / 2002$ & $27 / 3 / 2006$ & 203.981 .880 & 1,40 & $285.574 .632,00$ \\
\hline Nelfinavir 250mg & $05 / 03$ & $11 / 5 / 2007$ & 256.728 .580 & 0,62 & $159.171 .719,60$ \\
\hline Ritonavir sol.oral & $24 / 4 / 2003$ & $24 / 4 / 2003$ & 13.347 & 96,97 & $1.294 .258,59$ \\
\hline Total & $23 / 3 / 2001$ & $26 / 7 / 2007$ & & & $705.545 .614,11$ \\
\hline
\end{tabular}

Fonte: SIOPS - Sistema de Informações sobre Orçamentos Públicos em Saúde 1 - Conversão feita com base no dólar médio de $2006(\$ 1,00=R \$ 2,18)$

Foram feitas duas hipóteses para o cálculo dos royalties. Inicialmente, estimou-se que o preço adicional que o Ministério da Saúde pagou foi de $5 \%$ de royalties no valor total da compra realizada de cada produto. Trata-se de um valor de cálculo de royalty supostamente inferior ao praticado pela maioria das empresas, já que esse valor foi estimado com base nos valores praticados para negociação de licença compulsória, segundo o autor 
James Love(24). Usando essa estimativa, o prejuízo causado pelo instituto da patente pipeline, entre 2001 e 2007, foi de, aproximadamente, US\$ 35,3 milhões de dólares (valor total das aquisições US\$705.545.614,11, registrado na Tabela 1, vezes 5\%).

Utilizando-se outra forma de cálculo para o prejuízo hipotético mais realista, por levar em conta os preços prêmios médios cobrados pelas empresas monopolistas ao MS, isto é, a diferença entre estes e os preços mínimos praticados no mercado internacional, os prejuízos foram muito maiores. Como parâmetros de comparação para este novo cálculo, foram identificados em duas bases de dados diferentes os preços mínimos para os mesmos produtos praticados no mercado internacional. As bases são as da Organização Mundial da Saúde (OMS) e da organização não governamental Médicos Sem Fronteiras (MSF)(25). Essas organizações divulgam todos os anos uma lista de preços mínimos praticados nas compras internacionais. Estes valores foram registrados na Tabela 2. Nesta mesma tabela, registramos o preço médio pago pelo governo e as diferenças entre estes preços pagos pelo governo e os preços mínimos por unidades.

\section{Tabela 2: Preços mínimos obtidos pela OMS e MSF dos ARV selecionados (US\$) - 2006}

\begin{tabular}{|c|c|c|c|c|c|}
\hline Medicamento & $\begin{array}{l}\text { Preço/ } \\
\text { unidade }^{1} \\
\text { (US\$) }\end{array}$ & $\begin{array}{l}\text { Preço/ } \\
\text { Mínimo } \\
\text { OMS(2) }\end{array}$ & $\ddot{A}(1)-(2)$ & $\begin{array}{c}\text { Preço Mínimo } \\
\text { MSF } \\
\text { (3) }\end{array}$ & $A ̈(1)-(3)$ \\
\hline Abacavir Sol.Oral & 46,30 & 31,44 & 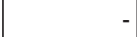 & 20,40 & 25,9 \\
\hline Abacavir 300mg & 2,56 & 0,83 & 1,73 & 0,59 & 1,97 \\
\hline Amprenavir Sol.Oral & 102,64 & - & - & - & - \\
\hline Amprenavir $150 \mathrm{mg}$ & 0,85 & - & - & - & - \\
\hline Efavirenz 600mg & 2,160 & 0,69 & 1,47 & 0,51 & 1,65 \\
\hline Efavirenz 200mg & 1,06 & 0,28 & 0,78 & 0,19 & 0,87 \\
\hline Efavirenz sol.oral & 32,80 & 16,92 & 15,88 & 12,42 & 20,38 \\
\hline Lopinavir/r 133/33mg & 1,40 & 0,69 & 0,71 & 0,23 & 1,17 \\
\hline Nelfinavir 250mg & 0,62 & 0,22 & 0,4 & 0,28 & 0,34 \\
\hline Ritonavir sol.oral & 96,97 & - & - & 223,20 & $-126,23$ \\
\hline
\end{tabular}

Fonte: OMS - Sources and prices of selected medicines and diagnostics for people living with HIV/AIDS - 2006

MSF - Untangling the web of price reductions: a pricing guide for the purchase of ARVs for developing countries de julho de 2007

1 - Preço médio pago pelo Ministério da Saúde entre 2001 e 2007

(24) LOVE, James. Compulsory licensing of patentes in the context of capacity building. In: ROUND OF THE HIV/AIDS TECHNOLOGICAL NETWORK, 1. 2005, Rio de Janeiro. Anais... Rio de Janeiro, 25-28 jan. 2005.

(25) MÉDICOS SEM FRONTEIRAS. Untangling the web of price reductions: a pricing guide for the purchase of ARVs for developing countries. Genebra: MSF, 2006. Disponível em: <http:// www.doctorswithoutborders.org/publications/article.cfm?id=3728\&cat=special-report>. 
Os Gráficos 1 e 2 evidenciam as diferenças de preços praticados e preços mínimos do medicamento com o instituto da patente pipeline, com base nos preços mínimos da OMS e MSF, respectivamente. Isto é, a diferença do que foi realmente pago pelo governo brasileiro e o quanto seria pago se o governo tivesse comprado pelos preços mínimos praticados no mercado internacional em termos percentuais.

\section{Gráfico 1: Diferença paga como prêmio pelo instituto da patente pipeline por ARV selecionado com base no preço mínimo da OMS, 2001-2007 (\%)}

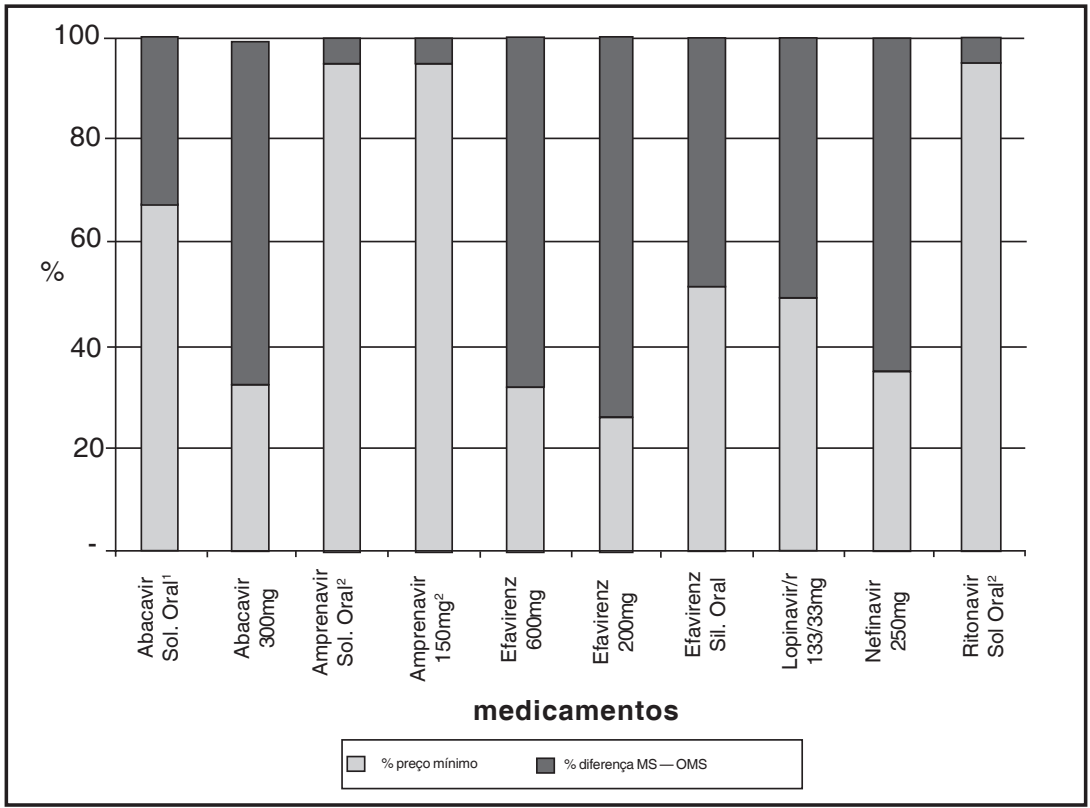

1 - Medicamento com cotação apenas para 2005

2 - Medicamentos sem cotação de preço para OMS, nesse caso, foi utilizado o royalties de $5 \%$ para cálculo do custo do instituto da patente pipeline.

Obs.: a - Para os medicamentos sem cotação de preço para OMS e/ou MSF, nesse caso, foi utilizado o royalties de $5 \%$ para cálculo do custo do instituto da patente pipeline; $\mathrm{b}$ - Conversão feita com base no dólar médio de $2006(\$ 1,00=\mathrm{R} \$ 2,18)$; c Cálculo feito com base no preço mais barato conseguido em junho de 2006 pela OMS

Analisando o Gráfico 1, dos 10 medicamentos antiretrovirais adquiridos pelo MS entre 2001 e 2007, três não apresentavam cotação de preços na OMS por não estarem na listagem de medicamentos para AIDS da Organização 
(amprenavir solução oral e 150mg e o ritonavir solução oral(26) e, por isso, para efeito de cálculo do sobrepreço, foi adotado o percentual de $5 \%$ a título de royalties pelos motivos já citados anteriormente. Entre os demais ARVs, quatro apresentam preço mínimo OMS entre $20 \%$ e $40 \%$ inferiores ao preço médio pago pelo MS. Outros dois (efavirenz solução oral e lopinavir/r) apresentam preço mínimo da OMS entre $40 \%$ e $60 \%$ inferiores ao preço do MS. Por fim, o abacavir solução oral apresenta a menor diferença entre os preços, tendo o preço mínimo da OMS inferior em cerca de $65 \%$ do preço médio pago pelo MS.

\section{Gráfico 2: Diferença paga como prêmio pelo instituto da patente pipeline por ARV selecionado, com base no preço MSF, 2001-2007}

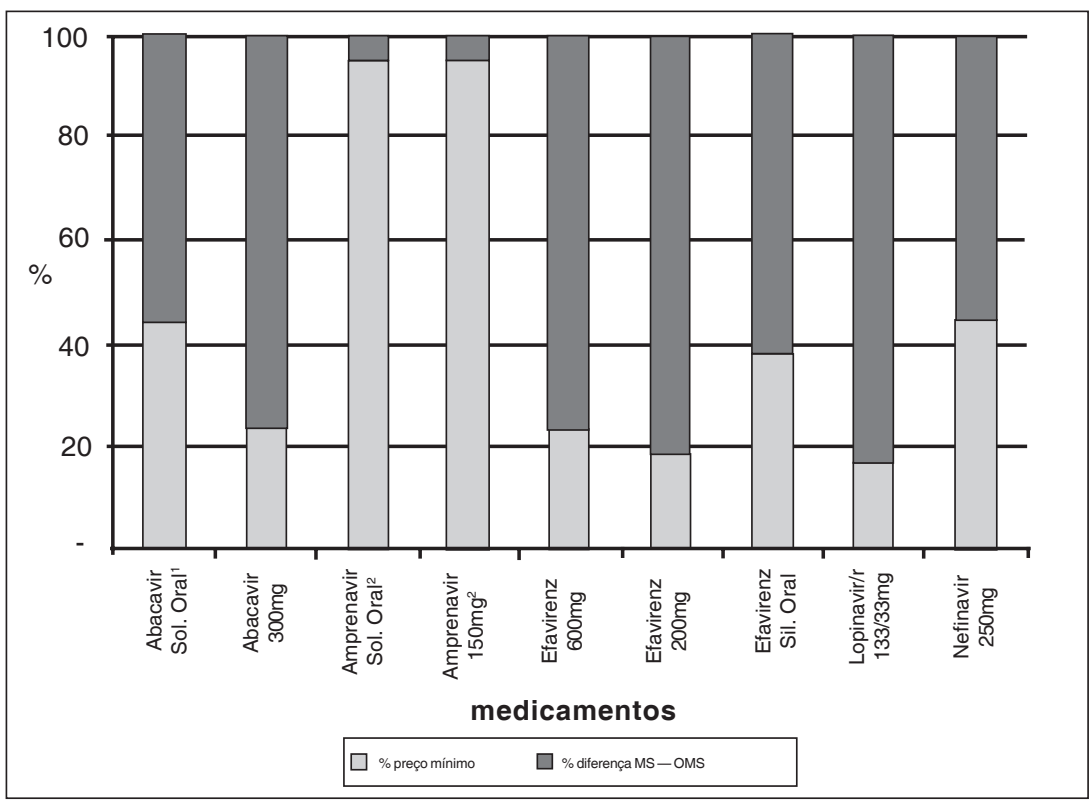

1 - Medicamento com cotação apenas para 2005

2 - Medicamentos sem cotação de preço para OMS, nesse caso, foi utilizado o royalties de $5 \%$ para cálculo do custo do instituto da patente pipeline.

Obs.: a - Para os medicamentos sem cotação de preço para OMS e/ou MSF, nesse caso, foi utilizado o royalties de $5 \%$ para cálculo do custo do instituto da patente pipeline; $b-$ Conversão feita com base no dólar médio de $2006(\$ 1,00=R \$ 2,18) ; c-$ Cálculo feito com base no preço mais barato conseguido em junho de 2006 pela OMS

(26) Existe apenas um registro de compra do ritonavir solução oral realizado por inexigibilidade em 2003 junto a Abbott. As demais compras deste medicamento foram realizadas por pregão nos anos de 2004 e 2005, adquiridos junto a Cristália e, por isso, não foram considerados para efeito de cálculo do custo pipeline. 
Comparando os preços médios pagos pelos MS com os preços mínimos cotados no banco de preços de MSF, pode-se notar que a diferença entre eles é maior do que quando comparamos com os preços da OMS. As únicas exceções são o nelfinavir 250mg e o ritonavir solução oral. Este segundo não aparece no gráfico pelo fato de que sua cotação no MSF ser superior ao preço pago pelo MS.

Dos demais medicamentos, dois não apresentavam cotação de preços no MSF por não estarem na listagem de medicamentos para AIDS desta Instituição (amprenavir solução oral e 150mg) e por isso, para efeito de cálculo do sobrepreço, foi adotado o percentual de $5 \%$ a título de royalties. Dois medicamentos (efavirenz 200mg e lopinavir/r) apresentaram os preços mínimos do MSF inferior a $20 \%$ do preço médio pago pelo MS. Outros três (abacavir 300mg, efavirenz 600mg e o efavirenz solução oral) apresentaram os preços mínimos do MSF entre $20 \%$ e $40 \%$ inferiores ao preço médio pago pelo MS. Por fim, o abacavir solução oral e o nelfinavir $250 \mathrm{mg}$ apresentam as menores diferenças, os preços MSF representam um pouco mais de $40 \%$ do preço médio pago pelo MS.

O outro cálculo hipotético do prejuízo total do causado pelo instituto da patente pipeline pode ser feito multiplicando a diferença entre o preço praticado e o preço mínimo de cada uma das organizações pela quantidade adquirida. Em termos de valores brutos, o prejuízo chegou aproximadamente a US\$ 420 milhões (a partir da comparação com os preços mínimos da OMS) e US\$519 milhões (preços mínimos da MSF). Ou seja, um prejuízo que equivale a mais de dez vezes a estimativa anterior (US\$ 35 milhões).

Pode-se interpretar o pipeline como uma medida de irracionalidade do uso de recursos públicos no Brasil, que poderiam estar sendo utilizados para compra de outros medicamentos ou para investimento em P\&D. Ainda que este cálculo seja hipotético, seu valor representa, respectivamente, 5,5 e 6,8 vezes o valor gasto em P\&D por ano, realizado pelo conjunto da indústria farmacêutica no Brasil, cerca de US\$ 77 milhões de dólares em $2003^{(27)}$. Esse prejuízo estimado também foi equivalente, respectivamente, a 3,6 e 4,4 vezes ao valor dos recursos públicos destinados pelo governo à inovação, através dos editais de financiamento no período 2003-2006 ${ }^{(28)}$.

Considerando que o caso discutido abrange apenas o total da compra de cinco medicamentos antirretrovirais, no período entre 2001 e 2007, pelo Programa Nacional de DST/Aids e que o número de patentes pipeline de medicamentos, como visto, chega a 1.182, pode-se supor que o país esteja tendo um prejuízo na ordem dos bilhões de dólares.

(27) INSTITUTO BRASILEIRO DE GEOGRAFIA E ESTATÍSTICA. Pesquisa Industrial de Inovação Tecnológica (PINTEC) 2003. Rio de Janeiro: IBGE, 2005.

(28) PARANHOS, Julia; LOPES, Rodrigo. Políticas de financiamento à inovação na indústria farmacêutica. In: SEMINÁRIO DE ECONOMIA INDUSTRIAL, 8., 2007. Araraquara. Anais... Araraquara: GEEIN/UNESP, 15-19 ago. 2007. 
Por exemplo, o medicamento mesilato de imatinib, comercializado pelo nome Glivec (Novartis), é utilizado para o tratamento de leucemia mielóide crônica. A patente do princípio ativo é de 1992 e foi protegida no Brasil pelo instituto da patente pipeline. O custo do tratamento por paciente/mês no país em 2006 era de aproximadamente $\mathrm{R} \$ 10.000^{(29)}$, mesmo existindo opções genéricas do produto onde os custos não ultrpassariam US $\$ 200$ por paciente/mês ${ }^{(30)}$. Podem ser citados ainda outros exemplos de produtos presentes na lista de medicamentos excepcionais ou de alto custo do Ministério da Saúde, tais como a olanzapina, ziprasidona, atorvastatina, donepezila e leflunomida. Todos têm versões genéricas disponíveis em mercado internacional a preços mais baixos, sendo o caso da olanzapina emblemático: o custo do tratamento por paciente por mês no Brasil (aproximadamente $R \$ 1.800,00$ ) chega a ser 60 vezes mais alto do que a versão genérica indiana (aproximadamente $R \$ 30,00)^{(31)}$.

Desta forma, fica claro que o instituto de patentes pipeline está beneficiando, principalmente, os titulares das patentes, enquanto o governo está pagando preços prêmio elevados que são prejudiciais ao bem-estar da sociedade.

\section{INCONSONÂNCIA DO INSTITUTO DE PATENTES PIPELINE COM A CONSTITUIÇÃO FEDERAL DE 1988 E COM O DIREITO INTERNACIONAL}

Os arts. 230 e 231 da Lei de Propriedade Industrial vem sendo questionado no que se refere a sua constitucionalidade, especialmente frente à violação dos princípios constitucionais que regem a propriedade industrial (art. 5ㅇ, XXIX); à violação do devido processo legal substantivo (art. 5º, LIV) e pela afronta ao princípio da isonomia (art. 5ํㅜ).

A Constituição Federal de 1988, ao determinar a proteção da propriedade e, por conseguinte, à propriedade industrial, estabeleceu também as diretrizes e os objetivos de tal proteção, associando-a a necessária atenção ao interesse público, conforme explícito em dois parágrafos do art. 5을

- A propriedade atenderá a sua função social (XXIII);

- A lei assegurará aos autores de inventos industriais privilégio temporário para sua utilização, bem como proteção às criações industriais, à

(29) BRASIL. Ministério da Saúde. Banco de preços em saúde. Brasília: Ministério da Saúde. Disponível em: <http://bpreco.saude.gov.br/bprefd/owa/consulta.inicio?p_tipo_consulta=1\&p_lingua=1\&p_cambio=1>. (30) MÉDICOS SEM FRONTEIRAS. Q \& A on Patents in India and the Novartis Case. Geneva, 20 dez. 2006. Disponível em: <http://www.msf.org/msfinternational/invoke.cfm?objectid=A05B02CF5056-AA77-6CA9A174A5C4E2F7\&component=toolkit.article\&method=full_html>.

(31) MIRANDA, Pedro Henrique Marques Villardi. Perguntas e respostas sobre patentes pipeline: como afetam sua saúde? Rio de Janeiro: ABIA, 2009. Disponível em: <http://www.abiaids.org.br/ _img/media/PergResp_PIPELINE_PT.pdf>. 
propriedade das marcas, aos nomes de empresas e a outros signos distintivos, tendo em vista o interesse social e o desenvolvimento tecnológico e econômico do País (XXIX).

Portanto, há a necessidade de que a proteção patentária atenda ao interesse social, o que não ocorre no presente caso. Como já visto, o instituto das patentes pipeline permite a proteção de medicamentos e alimentos sem a análise material, ademais de oferecer proteção ao que já estava em domínio público no Brasil. Assim, a concessão do instituto da patente pipeline viola frontalmente o princípio da inderrogabilidade do domínio público, pelo qual um conhecimento, após ter entrado em domínio público, não pode mais dele ser retirado(32). O ingresso no domínio público faz com que determinado bem se torne comum a todos e a coletividade adquire o direito de mantê-la disponível, impedindo sua apropriação individual.

Fato que merece destaque é a adoção no Brasil do princípio da novidade absoluta em matéria de patente, ou seja, se a tecnologia para a qual se pede proteção já entrou no estado da técnica em qualquer lugar, em qualquer tempo, não existe privilégio. A novidade absoluta considera que a invenção não pode ter se tornado pública em qualquer país, portanto abrangendo o que for encontrado na literatura de qualquer país ${ }^{(33)}$. Este princípio está previsto no Tratado de Cooperação em Matéria de Patentes (PCT) da Organização Mundial de Propriedade Intelectual — do qual o Brasil também é signatário.

Soma-se a isso o fato de que a legislação brasileira de propriedade industrial entende como pertencente ao estado da técnica (art. 11, 2º 0 conteúdo do pedido de patente depositado, mesmo não publicado, a partir da data do depósito ou da prioridade reivindicada. Sendo assim, pedidos de patentes feitos no exterior em qualquer período anterior à entrada em vigor da nova lei de prioridade industrial brasileira já se encontravam no rol de invenções pertencentes ao estado da técnica no Brasil.

Sobre o viés jurídico desenvolvido até aqui, por fim, apontamos a incompatibilidade do instituto das patentes pipeline com relação a Declaração Universal dos Direitos do Homem. Esta Declaração estabelece em seu art. 27 os propósitos de "tomar parte livremente na vida cultural da comunidade, de fruir as artes e de participar no progresso científico e nos benefícios que deste resultam". Sendo assim, o conhecimento em domínio público é essencial para garantia desse direito.

Outras violações constitucionais podem ser apontadas: os arts. 230 e 231 da Lei de Propriedade Industrial violam o princípio do devido processo

(32) BARBOSA, Denis Borges. Inconstitucionalidade das patentes pipeline. 2006, p. 22. Disponível em: <http://denisbarbosa.addr.com/pipeline.pdf>.

(33) DI BLASI, Gabriela; GARCIA, Mario S.; MENDES, Paulo Parente M. A. A propriedade industrial: os sistemas de marcas, patentes e desenhos industriais analisados a partir da Lei 9279/96, Rio de Janeiro: Forense, 2002. p. 124. 
legal substantivo, representados na razoabilidade e proporcionalidade das medidas, ao permitir a proteção patentária sem a análise dos requisitos materiais e à revelia dos princípios constitucionais que determinam a função social da propriedade. A Constituição Federal assim prevê, novamente, em seu art. $5^{\circ}$ que "ninguém será privado da liberdade e de seus bens sem 0 devido processo legal (LIV)".

A proporcionalidade e a razoabilidade de medidas legislativas e administrativas devem ser apreciadas de acordo com o princípio do devido processo legal substantivo, cuja interpretação tem sido desenvolvida pelo Supremo Tribunal Federal e constitui parâmetro para análise de coerência constitucional dos referidos atos.

Por fim, cumpre ressaltar que o instituto da patente pipeline viola também o princípio da isonomia, consubstanciado no caput do art. $5^{\circ}$ da Constituição Federal, ao permitir tratamentos diferenciados entre nacionais e estrangeiros. Houve uma clara desigualdade de tratamento entre os depositantes nacionais e estrangeiros no que tange ao instituto da patente pipeline. Esta desigualdade ficou evidenciada na medida em que o depósito do inventor nacional só foi aceito mediante o preenchimento dos requisitos de patenteabilidade estabelecidos na lei nacional (art. $8^{\circ}, \mathrm{LPI}$ ), enquanto os depositantes estrangeiros foram submetidos apenas aos requisitos exigidos nos países de origem, que, em muitos casos, se diferenciam dos previstos no Brasil.

Vale ressaltar que a Convenção da União de Paris (CUP), versão Estocolmo (1967), que estabelece princípios como a da independência das patentes (Art. 40 bis), segundo o qual a patente concedida em um país não tem relação alguma com a patente concedida em outro país, ou seja, a patente é um título cuja validade é nacional.

Dessa forma, ao não ser submetido ao exame no Brasil, segundo critérios de análise nacionalmente definidos, as patentes pipeline foram concedidas com base em critérios de outros países e, portanto, estão igualmente em desacordo com a CUP. É importante ressaltar que países como França e Bélgica concedem patentes sem, sequer, fazer análise de mérito; Luxemburgo concede patentes no prazo de uma semana(34)(35).

O mecanismo pipeline não é apenas uma afronta a um dos princípios da CUP, como também abre um precedente extremamente negativo rumo à patente internacional.

(34) AMARAL, Luciene. Concessão de patentes de medicamentos via Pipeline. Rio de Janeiro: FIOCRUZ, 2005.

(35) REIS, Renata C. C. As vozes do laboratório: a perspectiva dos pesquisadores de biotecnologia da Universidade Estadual do Norte Fluminense Darcy Ribeiro e Universidade Livre de Bruxelas sobre patentes e pesquisas em inovação. Dissertação (Mestrado). Universidade Estadual do Norte Fluminense Darcy Ribeiro, UENF, Campos dos Goytacazes, 2005. 


\section{CONTESTAÇÃO DAS PATENTES PIPELINE PELA SOCIEDADE CIVIL BRASILEIRA E A ADI 4.324}

No final de 2007, a Federação Nacional dos Farmacêuticos (FENAFAR), em nome do Grupo de Trabalho sobre Propriedade Intelectual da Rede Brasileira pela Integração dos Povos (GTPI/Rebrip), ${ }^{(36)}$ apresentou na Procuradoria Geral da República uma representação ${ }^{(37)}$ que demonstra a inconstitucionalidade dos arts. 230 e 231 da LPI. A representação demandava ao Procurador Geral da República que ingressasse com uma ação direta de inconstitucionalidade (ADI) questionando o mecanismo pipeline no Supremo Tribunal Federal (STF), uma vez que organizações da sociedade civil não possuem legitimidade para ajuizar este tipo de ação.

A ADI é um instrumento judicial que permite o controle concentrado de constitucionalidade de uma lei ou ato normativo em âmbito federal, ou seja, por meio desta ação, é possível questionar se determinada legislação federal ou estadual - está ou não de acordo com a Constituição Federal brasileira. A ADI é julgada diretamente pelo STF e a declaração de inconstitucionalidade resulta por retirar a norma questionada do ordenamento jurídico e impedir que esta produza quaisquer efeitos ${ }^{(38)}$. A representação também contou com o apoio de várias outras organizações da sociedade civil internacional e de especialistas ${ }^{(39)}$.

(36) A REBRIP é uma articulação de ONGs, movimentos sociais, entidades sindicais e associações profissionais autônomas e pluralistas, que atuam sobre os processos de integração regional e comércio, comprometidas com a construção de uma sociedade democrática pautada em um desenvolvimento econômico, social, cultural, ético e ambientalmente sustentável. Estas entidades buscam alternativas de integração opostas à lógica da liberalização comercial e financeira predominante nos acordos econômicos atualmente em curso. Devido à crescente discussão sobre propriedade intelectual no âmbito internacional e o impacto causado pelos acordos internacionais no âmbito nacional, demonstrou-se necessária a criação de um grupo destinado à discussão de temas tocantes à propriedade intelectual e sua repercussão no acesso ao conhecimento pela sociedade brasileira. Neste contexto, foi criado o GTPI, coordenado pela Associação Brasileira Interdisciplinar de AIDS — ABIA, desde a sua criação em 2003 (tendo sido reconduzida à coordenação nas duas últimas assembleias da REBRIP). Organizações que compõem o GTPI/Rebrip: Nacionais: ABIA, GIV, GAPASP, GAPA-RS, GESTOS, GRAB, Pela Vidda-SP, Idec, Conectas Direitos Humanos, RNP+ Maranhão, Federação Nacional dos Farmacêuticos. Internacionais: Médicos Sem Fronteiras e Oxfam.

(37) Representação disponível na íntegra na página eletrônica da Conectas Direitos Humanos: CONECTAS DIREITOS HUMANOS. Organizações contestam a constitucionalidade da Lei de Propriedade intelectual, cit.

(38) CHAVES, G. C; VIEIRA, M. F; REIS, R. Acesso a medicamentos e propriedade intelectual no Brasil: reflexões e estratégias da sociedade civil. SUR - Revista Internacional de Direitos Humanos, São Paulo, ano 5, n. 8, p. 170-198, jun. 2008. Disponível em: <www.surjournal.org>. Acesso em: 15 fev. 2010.

(39) Os grupos e pesquisadores que enviaram cartas de apoio foram: 1 - Fundación IFARMA Colômbia; Oxfam International; Thai network of people living with HIV/AIDS; (TNP+); AIDS ACCESS Foundation; Thai Foundation for consumers; Thai Rural Doctors society; Thai Chronic renal failure network; Thai Alternative Agriculture network; Thai Parents network; Thai Rural Pharmacist society; Thai NGOs Coalition on AIDS; FTA Watch; Drug Study Group; Prof. Kevin Outterson (Boston University School of Law); Prof. Brook K. Baker (Northeastern University School of Law); Knowledge Ecology International (KEI); Third World Network; Lawyers Collective HIV/AIDS Unit; Indian Network for People Living with HIV/AIDS; Delhi Network of Positive People; Alternative Law Forum; Cancer Patients Aid Association e ActionAID India. 
De fato, o Brasil, ao longo dos últimos anos, tem exercido um importante papel de liderança para que as regras de proteção à propriedade intelectual adotadas em âmbito internacional não ponham em risco os sistemas de saúde pública nos países em desenvolvimento. No entanto, em âmbito interno, regras como as patentes pipeline tem sido uma flagrante contradição com a postura adotada pelo país em foros internacionais. O questionamento judicial dessas patentes, absolutamente contrárias ao interesse público, é mais um passo no caminho de fazer prevalecer dentro do Brasil o discurso já adotado na arena internacional.

Finalmente, em abril de 2009, o Procurador Geral da República - à época Antônio Fernando Barros e Silva de Souza - entrou com a ADI 4.234 questionando a constitucionalidade do mecanismo pipeline.

Como efeito, diferentes organizações e associações de interesse privado e público apresentaram amicus curiae à ação no intuito de influenciar a decisão a ser tomada pelos ministros, com argumentos contra e a favor. Dentre as de interesse privado estão a Associação Brasileira de Sementes e Mudas (ABRASEM), Associação Brasileira de Química Fina (ABIFINA), Associação da Indústria Farmacêutica de Pesquisa (INTERFARMA), Associação Brasileira das Indústrias de Medicamentos Genéricos (Pro Genéricos), Associação Brasileira de Propriedade Intelectual (ABPI) e Associação Nacional de Defesa Vegetal (ANDEF) ${ }^{(40)}$.

Organizações de interesse público, membros do GTPI/Rebrip, também apresentaram amicus curiae: a primeira petição foi coassinada pela CONECTAS Direitos Humanos e pelo GAPA São Paulo; e a segunda coassinaram a Associação Brasileira Interdisciplinar de Aids (ABIA), Médicos Sem Fronteiras Brasil (MSF), Grupo de Incentivo à Vida (GIV), GAPA RS, Instituto de Defesa do Consumidor (IDEC) e a Federação Nacional dos Farmacêuticos (FENAFAR). Vale ressaltar que a Agência Nacional de Vigilância Sanitária (ANVISA) também apresentou um amicus curiae. Até o presente momento, só foi admitida pelo STF a amicus da Associação da Indústria Farmacêutica de Pesquisa (INTERFARMA).

A Tabela 3 apresenta um resumo dos principais argumentos apresentados pelas organizações e associações supracitadas em seus respectivos amici curiae.

(40) A petição apresentada pela ANDEF, até a data de submissão do presente artigo, ainda não havia sido disponibilizada para consulta na página do STF e, portanto, não será analisada. 


\begin{tabular}{|c|c|c|}
\hline Associação & $\begin{array}{l}\text { Contra ou a favor da } \\
\text { inconstitucionalidade } \\
\text { das pipelines }\end{array}$ & Principais argumentos \\
\hline ABIFINA & A favor & 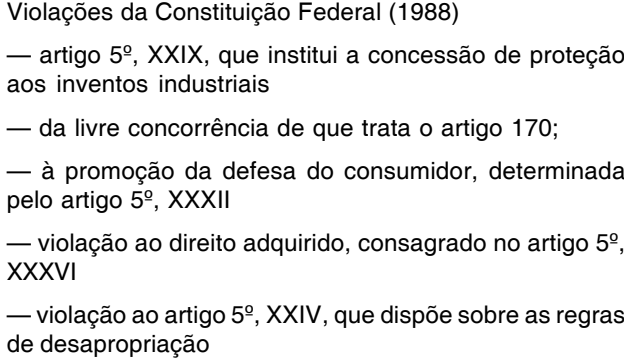 \\
\hline Pró-genéricos & A favor & $\begin{array}{l}\text { — violação do requisito da novidade, intrínseco ao } \\
\text { conceito do privilégio protegido constitucionalmente pelo } \\
\text { artigo } 5^{\circ}, \text { XXIX } \\
\text { — violação da defesa do consumidor, prevista no artigo } \\
5^{\circ} \text {, XXXII } \\
\text { — violação da função social da propriedade, estipulada } \\
\text { no artigo 5o e artigo } 170 \text {, III } \\
\text { - parecer da Comissão de Constituição, Justiça e } \\
\text { Cidadania do Senado Federal opinando pela rejeição do } \\
\text { mecanismo pipeline emitido na época de discussão da LPI }\end{array}$ \\
\hline $\begin{array}{l}\text { Conectas e } \\
\text { GAPA/SP }\end{array}$ & A favor & $\begin{array}{l}\text { Violação ao artigo } 5^{\circ}, \text { XXIX da Constituição Federal, uma } \\
\text { vez que não foram concedidas visando o interesse social e } \\
\text { o desenvolvimento econômico e tecnológico do país, como } \\
\text { impõe a cláusula finalística contida no texto constitucional } \\
\text { que determina a proteção às criações industriais }\end{array}$ \\
\hline $\begin{array}{l}\text { ABIA, MSF, } \\
\text { FENAFAR, } \\
\text { IDEC, GIV e } \\
\text { GAPA/RS }\end{array}$ & A favor & $\begin{array}{l}\text { - Violação do princípio da inderrogabilidade do domínio } \\
\text { público, pelo qual um conhecimento, após ter entrado em } \\
\text { domínio público, não pode mais dele ser retirado - violaria } \\
\text { o princípio do devido processo legal substantivo, } \\
\text { representado na razoabilidade e proporcionalidade das } \\
\text { medidas, ao permitir a proteção patentária sem a análise } \\
\text { dos requisitos materiais e à revelia dos princípios } \\
\text { constitucionais que determinam a função social da } \\
\text { propriedade } \\
\text { - Violação do princípio da isonomia, contido no caput do } \\
\text { artigo } 5^{\circ} \text { da Constituição Federal, ao permitir tratamento } \\
\text { diferenciado entre nacionais e estrangeiros - Impacto } \\
\text { negativo na vida dos brasileiros ao onerar o poder público, } \\
\text { dificultar o acesso a medicamento; gerar diminuição de } \\
\text { postos de trabalho e não gerar desenvolvimento do parque } \\
\text { tecnológico nacional. Dessa forma, contrariou o interesse } \\
\text { social e o desenvolvimento econômico e tecnológico do } \\
\text { país, sendo, portanto, contrário à Constituição Federal }\end{array}$ \\
\hline
\end{tabular}




\begin{tabular}{|c|c|c|}
\hline Associação & $\begin{array}{l}\text { Contra ou a favor da } \\
\text { inconstitucionalidade } \\
\text { das pipelines }\end{array}$ & Principais argumentos \\
\hline \multirow[b]{2}{*}{ ANVISA } & \multirow{2}{*}{ A favor } & \begin{tabular}{|l|} 
- ofensa ao critério constitucional da novidade, ofensa \\
à soberania nacional e ofensa ao direito adquirido
\end{tabular} \\
\hline & & $\begin{array}{l}\text { - apresentou fatos que demonstram o impacto das } \\
\text { patentes de revalidação no acesso a medicamentos }\end{array}$ \\
\hline \multirow[b]{3}{*}{ INTERFARMA } & \multirow[b]{3}{*}{ Contra } & $\begin{array}{l}\text { - inépcia da petição inicial por ausência de } \\
\text { fundamentação jurídica do pedido em relação a cada uma } \\
\text { das impugnações }\end{array}$ \\
\hline & & $\begin{array}{l}\text { - propugnou pela extinção do processo sem julgamento } \\
\text { de mérito }\end{array}$ \\
\hline & & $\begin{array}{l}\text { - pressupostos constitucionais relacionados ao interesse } \\
\text { social e ao desenvolvimento econômico e tecnológico do } \\
\text { país foram preenchidos: a) o interesse social foi atendido } \\
\text { especialmente pela imediata disponibilização de produtos } \\
\text { de tecnologia avançada no mercado brasileiro, incluindo } \\
\text { inúmeros medicamentos; b) o desenvolvimento econômico } \\
\text { e social do país ocorreu na medida em que o Brasil se } \\
\text { tornou, ao longo desses últimos anos, um dos principais } \\
\text { mercados farmacêuticos do mundo, alvo de maciços } \\
\text { investimentos estrangeiros e nacionais; c) o } \\
\text { desenvolvimento do país foi atingido pelo uso das novas } \\
\text { tecnologias disponibilizadas no mercado nacional }\end{array}$ \\
\hline \multirow{2}{*}{ ABRASEM } & \multirow{2}{*}{ Contra } & $\begin{array}{l}\text { - Inépcia da petição inicial, uma vez que esta não teria } \\
\text { indicado de modo suficiente os fundamentos jurídicos do } \\
\text { pedido em relação a cada uma das impugnações } \\
\text { formuladas. }\end{array}$ \\
\hline & & $\begin{array}{l}\text { - entendimento de que as patentes pipelines estimularam } \\
\text { o desenvolvimento econômico e social do país, nos termos } \\
\text { do artigo } 5^{\circ}, \text { XXIX da Constituição Federal, na medida em } \\
\text { que possibilitaram a inserção do Brasil no mundo } \\
\text { globalizado. }\end{array}$ \\
\hline \multirow{4}{*}{ ABPI } & \multirow{4}{*}{ Contra } & $\begin{array}{l}\text { - novidade é um requisito legal e não constitucional - } \\
\text { não ocorrência de efeito retroativo }\end{array}$ \\
\hline & & $\begin{array}{l}\text { - ausência de direito adquirido que impeça a lei de ser } \\
\text { alterada e proteção do usuário anterior }\end{array}$ \\
\hline & & $\begin{array}{l}\text { - mecanismo pipeline cumpre obrigação estabelecida no } \\
\text { Acordo TRIPS no artigo } 70.8 \text { (eventual declaração de } \\
\text { inconstitucionalidade poderia ensejar contencioso na OMC) }\end{array}$ \\
\hline & & $\begin{array}{l}\text { - declaração de inconstitucionalidade seria nociva na } \\
\text { ordem interna, afetando contratos firmados com base } \\
\text { nas patentes pipeline. }\end{array}$ \\
\hline
\end{tabular}

Fonte: Marcela Vieira, 2010. Proteção patentária para produtos e processos farmacêuticos: a questão da constitucionalidade das patentes pipeline. FAAP. 


\section{CONSIDERAÇÕES FINAIS}

Neste artigo, apresentaram-se argumentos de dupla perspectiva: da economia da saúde e do direito. Resultou claro, a partir de ambas as perspectivas analisadas, que a introdução do instituto da patente pipeline é frontalmente contra o interesse público. Do lado econômico, pode-se exemplificar essa perda de bem-estar pela sociedade através de um cálculo econômico hipotético de um sobrepreço que o Brasil pagou e ainda paga sem contrapartida de aumento de investimento em P\&D ou aumento do estoque de conhecimento público, motivações principais da natureza econômica do instituto da patente. Do lado do direito, observa-se que o instituto das patentes pipeline viola uma série de princípios constitucionais e também tratados internacionais dos quais o Brasil é signatário.

Ao contrário do que se poderia depreender da observação de um instituto transitório de 1996, a adoção do instituto de patentes pipeline produziu, e ainda produz efeitos, e seu questionamento judicial tem uma importância capital, mesmo passados 14 anos de sua adoção. Diversos medicamentos, como demonstrado, ainda estão sob monopólio de comercialização e assim permanecerão - onerando o Sistema Único de Saúde e impactando os orçamentos de muitos brasileiros - caso essa norma não seja revista.

A iniciativa de grupos da sociedade civil e a consequente proposição da ADI pelo Procurador Geral da República, contestando este mecanismo, colocam nas mãos do judiciário a possibilidade de revisão e reversão de um prejuízo incalculável e irreversível para a vida da população brasileira.

\section{REFERÊNCIAS BIBLIOGRÁFICAS}

AMARAL, Luciene. Concessão de patentes de medicamentos via Pipeline. Rio de Janeiro: FIOCRUZ, 2005.

ARROW, K. J. The economic implications of learning by doing. Review of Economic Studies, n. 29, p. 155-173, 1962.

BARBOSA, Denis Borges. Inconstitucionalidade das patentes pipeline. 2006. Disponível em: <http://denisbarbosa.addr.com/pipeline.pdf>.

BERMUDEZ, J. A. Z.; EPSZTEJN, R.; OLIVEIRA, M. A.; HASENCLEVER, L. O Acordo TRIPS da OMC e a proteção patentária no Brasil: mudanças recentes e implicações para a produção local e o acesso da população aos medicamentos. Rio de Janeiro: FIOCRUZ/ENSP, 2000.

BERMUDEZ, Jaz; OLIVEIRA, M. A; CHAVES, G. C. O acordo TRIPS da OMC e os desafios para a saúde pública. In: BERMUDEZ, Jaz; OLIVEIRA, M. A; 
ESTHER, A. (Org.). Acceso a medicamentos: derecho fundamental, papel del Estado. Rio de Janeiro: ENSP/FIOCRUZ, 2004. p. 69-89.

BRASIL. Decreto n. 1.355, de 30 de dezembro de 1994. Promulga a ata final que incorpora os resultados da rodada Uruguai de negociações comerciais multilaterais do GATT. Diário Oficial [da] República Federativa do Brasil, Poder Executivo, Brasília, DF, 31 dez. 1994.

BRASIL. Lei n. 9.279, de 14 de maio de 1996. Regula direitos e obrigações relativos a propriedade industrial. Diário Oficial [da] República Federativa do Brasil, Poder Executivo, Brasília, DF, 15 mai. 1996.

BRASIL. Ministério da Saúde. Banco de preços em saúde. Brasília: Ministério da Saúde. Disponível em: <http://bpreco.saude.gov.br/bprefd/owa/ consulta.inicio?p_tipo_consulta $=1 \& p$ _lingua $=1 \&$ p_cambio $=1>$.

BRASIL. Portaria no 879 de 24 de abril de 2007. Declara de interesse público os interesses de patentes sobre o efavirenz, para fins de licença compulsória para uso público não comercial. Disponível em: <https://www.in.gov.br/ materias/xml/do/secao1/2664533.xml>.

BRASIL. Portaria n. 886 de 24 de abril de 2007. Declara de interesse público os interesses de patentes sobre o efavirenz, para fins de licença compulsória para uso público não comercial. Disponível em http://portal.saude.gov.br/ portal/arquivos/pdf/portaria886_2007.pdf

BRASIL. Presidência da República. Casa Civil. Decreto n. 6.108, de 4 de maio de 2007. Concede licenciamento compulsório, por interesse público, de patentes referentes ao Efavirenz, para fins de uso público não-comercial. Diário Oficial da União, 7 maio 2007. Disponível em: <http:// www.planalto.gov.br/CCIVIL_03/_Ato2007-2010/2007/Decreto/D6108.htm>.

CHAUDHURI, S. Globalization of patent laws: flexibilities under TRIPS and changes in pharmaceutical patents in India. In: THE WTO and India's pharmaceuticals industry: patent protection, TRIPS and developing countries. Oxford: Oxford University Press, 2005.

CHAVES, G. C; VIEIRA, M. F; REIS, R. Acesso a medicamentos e propriedade intelectual no Brasil: reflexões e estratégias da sociedade civil. SUR - Revista Internacional de Direitos Humanos, São Paulo, ano 5, n. 8, p. 170-198, jun. 2008. Disponível em: <www.surjournal.org>. Acesso em: 15 fev. 2010.

CONECTAS DIREITOS HUMANOS. Guia prático sobre a OMC e outros acordos comerciais para defensores de direitos humanos. São Paulo, 2007. p. 13. Disponível em: <www.3dthree.org/pdf_3D/GuiaPratico.pdf>. Acesso em: 30 mar. 2010.

CONECTAS DIREITOS HUMANOS. Organizações contestam a constitucionalidade da Lei de Propriedade intelectual, 29 nov. 2007. Disponível em: <http://www.conectas.org/_noticia.php?not_id=192>. Acesso em: 22 jan. 2008. 
CORIAT, B.; ORSI, F.; ALMEIDA, C. TRIPS and the international public health controversies: issues and challenges. Industrial and Corporate Change Advance Access, Oxford, v. 15, n. 6, p. 1-30, nov. 2006.

DI BLASI, Gabriela; GARCIA, Mario S.; MENDES, Paulo Parente M. A. A propriedade industrial: os sistemas de marcas, patentes e desenhos industriais analisados a partir da Lei 9279/96, Rio de Janeiro: Forense, 2002.

GRANJEIRO, A.; TEIXEIRA, L.; BASTOS, F. I. et al. Sustentabilidade da política de acesso a antirretrovirais no Brasil. Revista de Saúde Pública, São Paulo, v. 40 (supl.), p. 60-69, abr. 2006.

GRUPO DE TRABALHO SOBRE PROPRIEDADE INTELECTUAL. Por que o Brasil paga mais por medicamentos importantes para a saúde pública? Rio de Janeiro: GTPI, 2006. Disponível em: <http://www.abiaids.org.br/_img/media/ patentes_GTPI.pdf>.

HASENCLEVER, L (Coord.). O Programa brasileiro de combate à AIDS e a experiência brasileira na produção local de medicamentos anti-retrovirais. Rio de Janeiro: UFRJ/ANRS, 2003. Mimeo.

INSTITUTO BRASILEIRO DE GEOGRAFIA E ESTATÍSTICA. Pesquisa Industrial de Inovação Tecnológica (PINTEC) 2003. Rio de Janeiro: IBGE, 2005.

LOVE, James. Compulsory licensing of patentes in the context of capacity building. In: ROUND OF THE HIV/AIDS TECHNOLOGICAL NETWORK, 1. 2005, Rio de Janeiro. Anais... Rio de Janeiro, 25-28 jan. 2005.

MÉDICOS SEM FRONTEIRAS. Guia de Preços para a Compra de ARVs para os países em desenvolvimento: untangling the web. 9. ed. Rio de Janeiro: MSF, 2006. Disponível em: <http://www.msf.org.br/campanha/ guia_precos06.pdf>.

MÉDICOS SEM FRONTEIRAS. Patentes de medicamentos em evidência: compartilhando informações práticas sobre patentes farmacêuticas. Rio de Janeiro: MSF, 2004. Disponível em: <http://www.msf.org.br/noticia/ relatorio_patente.pdf>.

MÉDICOS SEM FRONTEIRAS. $Q$ \& $A$ on Patents in India and the Novartis Case. Geneva, 20 dez. 2006. Disponível em: <http://www.msf.org/ msfinternational/invoke.cfm? objectid=A05B02CF-5056-AA776CA9A174A5C4E2F7\&component=toolkit.article\&method=full_html>.

MÉDICOS SEM FRONTEIRAS. Untangling the web of price reductions: a pricing guide for the purchase of ARVs for developing countries. Genebra: MSF, 2006. Disponível em: <http://www.doctorswithoutborders.org/ publications/article.cfm?id=3728\&cat=special-report $>$.

MIRANDA, Pedro Henrique Marques Villardi. Perguntas e respostas sobre patentes pipeline: como afetam sua saúde? Rio de Janeiro: ABIA, 2009. Disponível em: <http://www.abiaids.org.br/_img/media/PergResp_PIPELINE_PT.pdf>. 
NELSON, R. R. The simple economics of basic scientific research. The Journal of Political Economy, Chicago, v. 297, n. 67, 1959.

OLIVEIRA, M. A.; ESHER, A. Acesso universal ao tratamento para as pessoas vivendo com HIV e AIDS no Brasil. In: BERMUDEZ, Jaz; OLIVEIRA, M. A.; ESHER, A. (Orgs.). Acceso a medicamentos: derecho fundamental, papel del Estado. Rio de Janeiro: ENSP/Fiocruz, 2004.

OLIVEIRA, U. M. A proteção jurídica das invenções de medicamentos e de gêneros alimentícios. Porto Alegre: Síntese, 2000. 196 p.

ORSI, F.; HASENCLEVER, L; FIALHO, B.; TIGRE, P.; CORIAT, B. Intellectual property rights, anti-AIDS policy and generic drugs: lessons from brazilian public health program. In: MOATTI, J. P. et al. (Ed.). Economics of AIDS and Access to HIV/AIDS care in developing countrie: issues and Challenges. Paris: ANRS, 2003. v. 1, p. 109-136.

PARANHOS, Julia; LOPES, Rodrigo. Políticas de financiamento à inovação na indústria farmacêutica. In: SEMINÁRIO DE ECONOMIA INDUSTRIAL, 8., 2007. Araraquara. Anais... Araraquara: GEEIN/UNESP, 15-19 ago. 2007.

REIS, Renata C. C. As vozes do laboratório: a perspectiva dos pesquisadores de biotecnologia da Universidade Estadual do Norte Fluminense Darcy Ribeiro e Universidade Livre de Bruxelas sobre patentes e pesquisas em inovação. Dissertação (Mestrado). Universidade Estadual do Norte Fluminense Darcy Ribeiro, UENF, Campos dos Goytacazes, 2005. 